\title{
THE INTEGRATIVE CASE ANALYSIS MODEL FOR LINKING THEORY AND PRACTICE
}

\author{
Laura Boisen \\ Augsburg College \\ Maryann Syers \\ Augsburg College
}

This article introduces a case analysis model and field seminar format developed to enhance students' abilities to systematically integrate theory and practice in relation to their work with practicum clients. The authors draw upon learning theories and empirical research to explain the utility of the model and then describe specific components of the field seminar format including structured student assignments, associated classroom pedagogy, and an evaluation plan. The authors discuss the feasibility of implementing this model and offer considerations for further research.

FIELD EDUCATION PLAYS A CENTRAL ROLE in helping students integrate theory with practice in the field. Although many MSW programs conduct integrative field seminars to help achieve the task of integration, there are few explicit models detailing how this is best accomplished (Mary \& Herse, 1992; Mok, 1993; Walden \& Brown, 1985; Walters, Strom-Gottfried, \& Sullivan, 1998; Wilson, Birkenmaier, Banks, \& Berg-Weger, 2001). Second, there is little information available regarding how to determine whether the field integration objective was met or not. This paper will describe first, a case analysis model designed to enhance the student's ability to integrate theory with field practice and second, the field seminar format in which the model can be applied.Alsoincluded is a description of specific assignments created to facilitate the integration process and the evaluation plan used to monitor student success in achieving integration.

\section{Literature Review}

Social work education rests on the assumption that competent social work practice is grounded in the intentional use of theory. Practice informed by theory distinguishes professional social work from informal forms of helping. Theory expands the conceptualization of client problems, helps to organize large amounts of complex data, and provides direction for intervention (Berlin \& Marsh, 1993; Beder, 2000). Though commonly accepted that theory plays a central role in competent practice, social workeducation programs havestruggled to identify the means to assist students in linking theory taught in the classroom to practice in the field.

The conundrum of how to ensure the student's ability to link theory with practice has been a consistent theme throughout the social work education literature (Barsky, Rogers, Krysik, \& Langevin, 1997; Bogo \& Vayda, 
1989; Mary \& Herse, 1992; Raskin, 1994; Rogers \& McDonald, 1995; Rogers \& Thomlison, 1998). This represents a major educational challenge notonly for programs in this country, butalso for those throughout the world (Skolnik, Wayne, \& Raskin, 1999). Two of the most prevalent questions related to the integration of theory and practice concern where to locate the primary responsibility of integration in the curriculum and how to discern which strategies are most effective in enhancing students' abilities to integrate theory and practice.

\section{Where Is Integration Best Achieved?}

Three vehicles through which social work programs traditionally have sought to promote integration include (1) the practice methods course, (2) the practicum, and to a lesser extent, (3) the integrative field seminar.Someeducators have sought to encourage integration through the use of structured assignments in the classroom (Barsky et al., 1997). Barsky and his colleagues evaluated such an effort in a senior-year BSW 12-week methods course. Twenty-eight of the 83 students enrolled in the practice lab component of the course participated in the research. Toachieve integration, the authors used a practice lab composed of three components. The first was a communications lab in which students role-played both the roles of client and social worker. The second was a simulated client lab in which students role-played the social worker with a simulated client. The third was a computer lab used for practice and integration of research findings. Researchers used process recordings of client simulations, course evaluations, and focus groups to measure the change in students' ability to integrate theory with practice. Although findings demonstrated a positive change on all of the criteria used to evaluate the course, the authors found the greatest gains in the students' integration of theory and practice. However, students still indicated in focus group interviews a desire for more guidance in linking theory and practice, as well as more opportunities to do so.

Most often the goal of integration between field and course content has been designated for inclusion in the field practicum, with responsibility for achieving this objective delegated specifically to field instructors. With the changing context of social work practice, however, many field instructors are not well-equipped to facilitate the integration between class and field (Jarman-Rohde, McFall, Kolar, \& Strom, 1997; Reisch \& Jarman-Rohde, 2000). The advent of managed care, shrinking agency funding, and increasing workloads preclude the investment of field instructor time and attention essential to nurturing the integration process for students. In addition, many field instructors either fail to understand the necessity for theory and practice integration or feel inadequate to facilitate the process. For example, Bogo and Power (1992) found in a study of new field instructors that $31 \%$ believed that teaching theory was unimportant. Rogers and McDonald (1995) found in their study that most field instructors used teaching methods that were the most expedient rather than those that would have encouraged critical reflection by the students. Interestingly, they found that those instructors who used teaching methods based on students' selfreport rated students' preparation to assume the professional role significantly higher than those field instructors who used more reflective methods. The authors posit that relying on self-report rather than reflective methods 
may fail to capture a more accurate picture of the students' abilities.

The final venue in which social work programs attempt to provide integration is the integrative field seminar. The literature describes a number of integrative field seminar formats (Mary \& Herse, 1992; Walden \& Brown, 1985; Walters et al., 1998; Wilson et al., 2001), but few provide a structure that facilitates student competence in theory-based practice. Mary and Herse (1992) evaluated a weekly MSW field seminar designed to help students integrate course content with field practicum experience. Ninety-four students and their field instructors completed weekly checklists related to the course objectives (e.g., examination of support, treatment issues, and theory and practice integration). An end-of-the-year evaluation also asked for student feedback regarding which aspects of the seminar were most useful and which aspects needed to be improved. Only about one third of the students and faculty queried ranked knowledge integration among the top four objectives met in the seminar. In addition, students were more likely to perceive that the linkage of theory and practice occurred in those class sessions that were structured rather than unstructured. A critical limitation of this study was the lack of a direct measure of students' increased ability to draw on theory to ground practice decisions.

\section{Mastering Theory and Practice Integration}

Whether emphasis for the integration of theory and practice is placed in methods courses, the practicum, or the integrative field seminar, the question of how toassist students in mastering the integration of theory and practice still remains. Experience and research has demonstrated that this integration does not happen spontaneously as a result of students participating in a practicum experience alongside the classroom or seminarexperience (Mary \& Herse, 1992; Raschick, Maypole, \& Day, 1998; Rogers \& Thomlison, 1998), but rather through the use of structured classroom exercises (Raschick et al., 1998; Rogers \& Thomlison, 1998).

Raskin's most recent Delphi study found a strong consensus among experts in field education that schools of social work have failed to develop and apply "procedures that maximize integration of field and school" (1994, p. 81). These experts identified the development of such procedures to be among the top three priorities for field education in the 21st century, along with assistance to field instructors in furthering their students' ability to integrate theory and practice. Additionally, both students and field instructors have expressed the desire for further guidance in the integrative process (Barskyetal.,1997) and some (Rogers \& McDonald, 1995; Vayda \& Bogo, 1991) have urged the development of specific organizing frameworks to ground the integration of theory and practice in field programs.

Early field literature seemingly drew from disparate empirical research to assist faculty with the integration dilemma. For instance, Lowy, Bloksberg, and Walberg (1971) suggested that an interactional design that included components such as systematic sharing of information, team teaching, and peer consultation was the most powerful approach. Gordon and Gordon (1982) asserted that integration was enhanced when classroom and field instructors taught from a similar frame of reference. Birnbaum(1984) stressed the importance of both 
didactic and experiential learning activities to help students learn how to integrate theory and practice.

The current trend is to draw on theories of learning as the conceptual framework to assist in the creation of a model or the development of classroom strategies. Bogo and Vayda (1989, 1998) have developed one of the few models for assisting students with the integration process: the Integration of Theory and Practice (ITP) Loop. Using the stages of David Kolb's (1984) learning cycle, the ITP Loop prescribes a fourstep process for analyzing clientencounters. The process involves retrieving information related to the practice situation (concrete experience in Kolb's model), reflecting on personal associations related to the encounter (reflective observation), linking knowledge and theory with the practiceencounter(abstract conceptualization), and finally, selecting a professional response derived from the previous three steps (active experimentation).

Although all have not developed a model, field practitioners have used learning theory to improve their field education outcomes in other ways. Raschicketal.(1998) used Kolb's learning style model to develop teaching techniques to optimize learning in field placements. Enhancing the integration of theory and practice was notan initial goal of the research. However, after using Kolb's modeland evaluating the research data, they restructured their field seminars and added assignments thatemphasized theory and practice integration.

Other learning theory has been accessed as well. Believing that critical reflection is central to theory and practice integration, Rogers and Thomlison (1998) used the Gregorc (1982) learning typology to evaluate their teaching methods and assignments. They, too, found that operationalizing learning theory concepts in the field practicum assisted students in learning how to be more critically reflective. The authors developed structured exercises and assignments for their BSW field seminar that were meant to be responsive to the varied learning styles of their students as identified by the Gregorc instrument. The Gregorc (1982) learning styles instrument combines scores on tests of two continua of mental abilities (concreteness-abstractness and randomness-sequence) to suggest four different learning styles: concrete sequential, abstract sequential, concrete random, and abstract random. These categories are similar to Kolb's combination of the learning style dimensions of concrete experience, reflective observation, abstract conceptualization, and active experimentation into four respective quadrants: converger, assimilator, accommodator, and diverger. Rogers and Thomlison (1998) found that whereas the predominant learning style among their students was abstract random, a larger majority of students fell into the combined concrete categories (concrete random or concrete sequential) than the combined abstract categories (abstract random or abstract sequential).

The split between students operating out of the concrete or abstract learning styles poses a challenge to instructors structuring classroom exercises. However, Rogers and Thomlison (1998) conclude that "weneed to teach students how to integrate, how to reflect, how to think critically - that it doesn'tjusthappen automatically as a result of having a practicum experience juxtaposed with a classroom or seminar experience" (p. 5). Like Raschick et al. (1998), theseauthors suggest theneed to adopt teaching 
strategies that encourage students to develop their abstract conceptualization skills.

Thus, there is a growing interest in using learning theory as a basis for facilitating integration of theory and practice. Learning theories used most often have common denominators for areas covered such as how adults learn, specific learning style categories, and the role of reflection and experience. The model described in this paper is consistent with Kolb's learning theory (1984), as well as Bogo and Vayda's ITP Loop Model $(1989,1998)$. To enable students to integrate theory with practice, the model prescribes a structured cognitive process that requires students to critically reflect on their practice, link theory learned in the classroom with their practicum work, and use this process to guide subsequent work with clients.

\section{The Integrative Case Analysis Model}

The Integrative Case Analysis Model (ICAM) was created to give students a structured format in which they could develop their thinking and analyze their work with clients. It rests on the assumption that for students to learn to practice effectively, they must be able to consciously apply theory to their work with clients. Without the disciplined use of theory to undergird their clinical decision making, students are more likely to base their actions largely on a synthesis of personal experiences (Berlin \& Marsh, 1993). In the authors' experience, students, when presented with a client situation, leap to efforts to intervene before fully understanding the context of the problems presented. This then leads to an inadequate and ineffective response to the client issues. The model presented here seeks to compel students to reflect from a theoretical perspective, and in a sequential fashion, on their clients' situations to enhance the effectiveness of their interventions. First developed for use in the integrative seminar, it has also been used in practice methods courses and in training field instructors to assist students in theory-practice integration in the practicum.

Consistent with literature urging the need to pair field work with classroom teaching to enhance the integration of theory and practice (Gelfand, 1990; Rogers \& Thomlison, 1998; Tolson \& Kopp, 1988), theICAM was designed originally to be applied in concert with a student's field experience. Students in the family practice (clinical) concentration are introduced to this model in their final field placement in the MSW program. Alreadygrounded in human behavior in the social environment (HBSE) theory in their foundation year, students are learning a variety of advanced practice theories and models concurrent with this final field seminar.

Although the ICAM has several components, the centerpiece of the model is an understanding of theory and model and the complementary nature that must be present between the two for a coherent approach in working with a client. Students, however, must first be convinced of the significance of being able to identify and understand different theoretical approaches. This model explicitly illustrates how their work with clients is driven by hypotheses derived from HBSE and practice theory that then affects their effectiveness with clients.

Osmo and Landau (1998) have delineated three levels of awareness in social work decision making: the automatic, the intuitive, and the critical-evaluative. These authors argue that the critical-evaluative level is not only the 
most sophisticated, but the most conducive to effective professional practice. At this level, practitioners are deliberate in their "use of facts, prior knowledge, experience" (Osmo \& Landau, 1998, p. 3). The ICAM attempts to assist students to achieve this highest degree of decision-making sophistication through a series of assignments that seek to ascertain the student's analysis of the data. Not only do the students need to systematically analyze the data, but they must use a coherent approach from the initial step (the presenting problem) to the final step (termination). For example, the intervention strategies and goals must be coherent given the identified problem, hypotheses, and practice theory and model. Thus, one step must logically build on the previous.

Finally, the model provides a common framework and series of assignments from which both the field practicum instructor and field seminar instructor can teach. This approach has two advantages. Theory and practice integration is enhanced for students when there is coordination in method and format between the field practicum instructor and the field seminar instructor (Gordon \& Gordon, 1982). Providing a specific model and series of assignments with integration as the goal and theory as the centerpiece also reinforces to the field practicum instructor the value that the field program places on this approach. Offering specific assignments to achieve the goal of integration aids the field practicum instructor in meeting this expectation.

The first step in the model (see Figure 1) is for students to identify the presenting problem and relevant data. Students are then asked to identify the HBSE theory that has driven their questions in the data collection phase, as well as the theory that was the basis of the hypotheses they formulated.

Once hypotheses are formulated, possible practice theories and models are delineated, taking into account the specific cultural characteristics of the client(s), agency constraints, and student role constraints. To enhance their skills in distinguishing among a number of theories, students are encouraged to present theories in their purest form. This is true for the presentation of practice models as well. The delineation of the practice theories and models are evaluated on three criteria. First, the theory and model must be complementary. Second, they must logically build on the information that was gleaned as a result of the student's completion of previous steps in the model. Finally, theories and models must be sound in terms of current best practice knowledge.

Once the model is identified, the goals are delineated with thought given to how success, or lack thereof, will be measured from an evaluative standpoint. Only then are intervention strategies identified and discussed. This structure remedies students' inclination to gravitate to formulating interventions shortly after identifying the presenting problem and before they have adequately conceptualized the case. Outcomes are then evaluated and if the intervention was deemed to be successful, the termination phase is completed.

If the intervention was deemed to be unsuccessful, students are encouraged to revisit the definition of the problem, the analysis of the relevant data, and their hypotheses. They are encouraged to look at the data using other theory to see if that might change their approach. If the intervention was successful but new problems have emerged, students are 
instructed to start the process again with the new presenting problem. Embedded within this model and discussed in each assignment and presentation is culturally specific information, agency constraints, student role constraints, ethical dilemmas, and use-of-self issues.

\section{The Integrative Seminars}

The Integrative Case Analysis Model grew out of the authors' efforts to develop an integrative field seminar structure for the MSW fam- ily practice concentration that would assist students in applying knowledge and theory learned in the classroom directly to their work with clients in practicum. Historically in the field program, the integrative seminars have been based largely on the interactional design (Lowy etal., 1971) combining student peer support and consultation with the introduction of student- or faculty-selected special topics. As found by other field educators (Rogers \& Thomlison, 1998), however, thestudents did not

\section{FIGURE 1. Integrative Case Analysis Model}

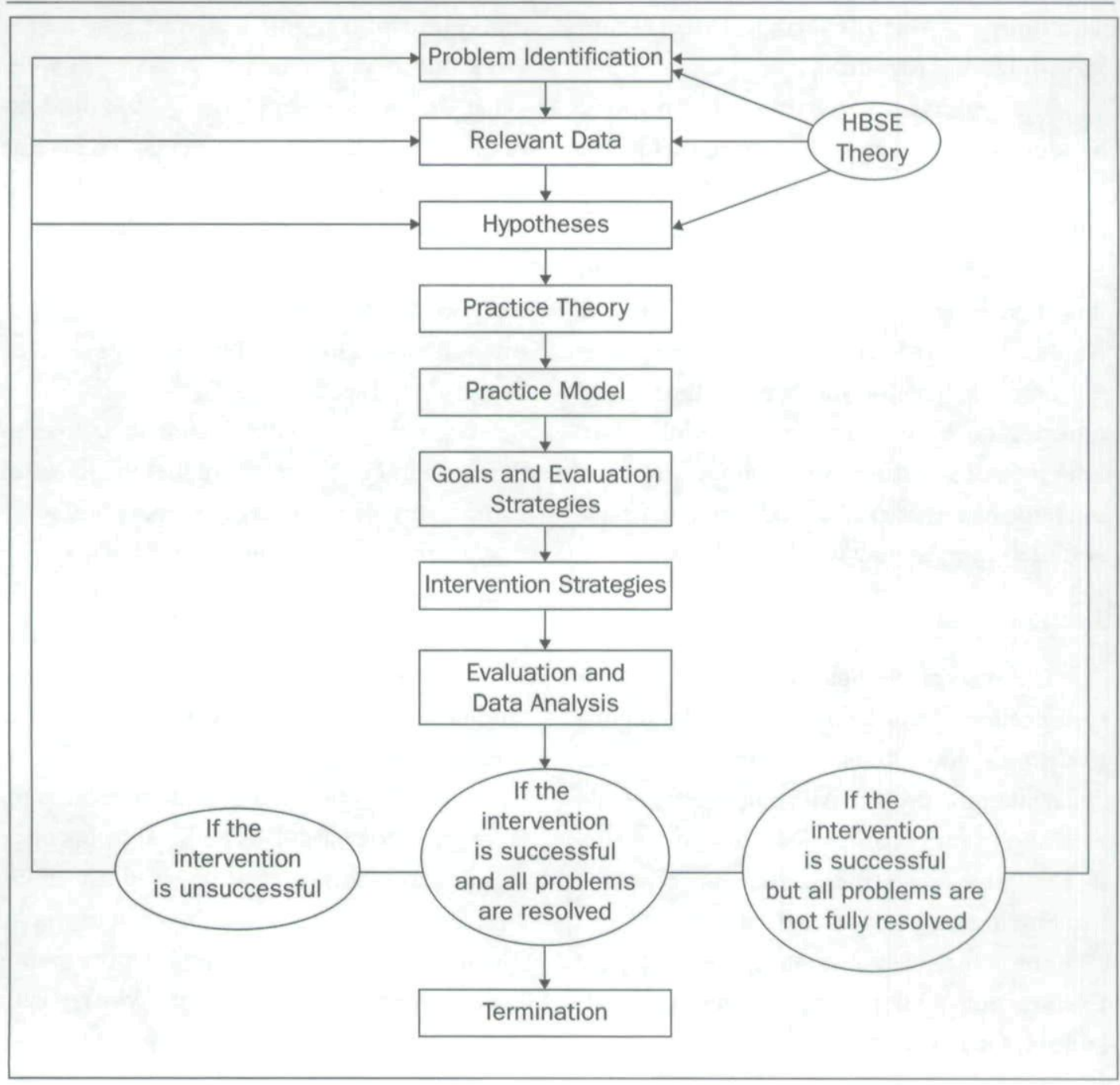


seem to learn how to integrate knowledge and practice or to critically reflect on their practice by virtue of participating in field practica in conjunction with the classroom experience. Rather, the students seemed to flounder in their efforts to use the knowledge and theory learned in their academic courses as groundwork for their case planning and implementation. Concerned that students needed to learn to think critically and systematically about their practica clients, the authors developed a seminar format comprised of three components and grounded in the ICAM: a series of structured assignments, a structured classroom pedagogical process, and an evaluation program.

The seminar was constructed to respond to educational research suggesting that learning is enhanced by providing a variety and repetition of learning experiences along with a conceptual framework to which students can link their experiences (Fortune, McCarthy, \& Abramson, 2001). Further, the seminar provides a structure in which students move through all four stages of Kolb's learning cycle (Kolb, 1984). This type of structure builds on the students' innate learning strengths and enhances their ability to learn in new ways.

\section{Assignments}

The integrative field seminar includes a series of four phases of practice assignments, two process recordings, and a final direct practice evaluation project. All assignments, while providing a variety of learning exercises, use the ICAM as the conceptual base to which students can link their practica experiences.

The phases of practice assignments require that students analyze a client interview, with specific focus given to each of the phases of practice: assessment, goal-setting and contracting, implementation or intervention, and termination and evaluation. The assignments are constructed to guide the students through a series of questions relevant to each of the four learning dimensions identified by Kolb (1984) and Smith and Kolb (1986) and adapted to social work by Bogo and Vayda (1989) in their ITP Loop model. In one set of questions, students must recall and describe their experience of the interview (concrete experience). This set includes questions such as, "How did you prepare for your meeting with the client? How did you plan to begin? Did your preparation work out as you planned? What went well? What did not go as planned?" A second set of questions encourages students to reflect on the interview (reflective observation). This set includes questions such as, "Describe your assessment of 'use of self' during this phase. Why did you feel this approach was appropriate in this situation? How do you think this affected the work with your client?"

Bogoand Vayda (1989) notein their description of their ITP Loop model that the phase of learning involving linkage of theory and practice (abstract conceptualizing in Kolb's model) is the most challenging for students and field instructors. Herein is the strength of the ICAM. By means of a structured series of questions, students learn to link theory with practice. The question format is structured linearly so questions build on one another and are redundant from phase to phase. This both reinforces prior learning and allows for teaching of idiosyncratic strategies for a particular phase. For example, each assignment asksstudents toidentify the following:presenting problem along with relevant data, hypotheses from which they are working, 
the practice theory and model they plan to use or are using, outcome goals, practice strategies they are using, use-of-self issues, relevant cultural considerations, and finally, ethical dilemmas and their responses to the dilemmas.

Finally, questions ask students to identify their plans for subsequent interactions with their client (active experimentation). These include questions such as "What modifications will you make in the future with this client and why?" and "How will the plan be modified in the areas where there has not been success? Or will it be modified? If not, explain."

In addition to the phases of practice assignments, students are required to complete two process recordings of a session with a client near the beginning and end of the field seminarclasses. The student provides a verbatim transcript of a substantial portion of a client session with a commentary that includes reflections on what wasoccurring (both with theclient, with thestudent, and in the interaction between the two), a description of thestudent's thoughts and feelings at that time, as well as a theoretical analysis of the student's interventions. The process recordings not only demonstrate students' level of skill, but also their ability to use practice knowledge and theory to analyze their discrete interventions with clients, thereby allowing faculty a more accurate evaluation of a student's preparedness for professional practice (Rogers \& McDonald, 1995).

The final assignment for the field seminar is the completion of a direct practice evaluation project. Theincreasing demand foraccountability in practice, in conjunction with research suggesting that "the practice evaluation skills taught in the classroom had only a minimal impact on the way in whichstudentspracticed" (Tolson\&Kopp, 1988 , p. 132), persuaded faculty to require that students demonstrate their ability to measure the effectiveness of their interventions in the practicum setting. The project requires that students once again demonstrate their ability to integrate theory with practice. Using one of their practicum client cases, students review the literature on the presenting problem and intervention methods used to address the problem. The students then must describe the practice theory and model they used with the client. Students develop an evaluation design in collaboration with theclient(s) in the goal-setting phase of practice. The student completes the evaluation and prepares a paper that includes the theoretical background, evaluation design, results, and discussion. The final phase of the project is a presentation and discussion of the project with the field seminar instructor and the field practicum instructor.

\section{Classroom Pedagogy}

Students in the integrative field seminar meet for a total of 32 hours over the course of the two trimesters. After the initial class session in which the students are introduced to the ICAM and given an opportunity to practice applying it to a fictional client case, each subsequent class is devoted to the application of the ICAM to the students' field practica cases, with analysis concentrating on one of the four phases of practice. Like other field models based on Kolb's model (Bogo \& Vayda, 1989, 1998; Raschicketal., 1998; Vayda \& Bogo, 1991), the structure provides for learning in all four of the learning styles and stages, though notnecessarily in the same order as recommended by Kolb (1984).

Each class session begins with a student presenting a client case from their field practicum following the ICAM format. A free-wheeling discussion then ensues in which students and 
faculty alike pose questions of the student and one another to enrich the understanding of the case. Students are encouraged to reflect on their experience with the client and to organize their knowledge of the case and reflections into a theoretical conceptualization of theclient problemand context. Thetheory, informed byadditionalfactors such as agency context, cultural considerations, and practitioner role and competence, directs the choice of practice model, client outcome goals, and interventions to be used.

After the client case has been thoroughly discussed from this one theoretical perspective, the seminar faculty invites the class to apply a different theoretical lens to the case. The class then discusses how using another theory modifies the choice of practice model, goals, and interventions. The students thereby gain facility in examining client situations from a number of theoretical perspectives, using the sameanalytic process. In addition to the above, the students discuss use-of-self and ethical concerns, as well as issues idiosyncratic to the particular phase of practice being examined.

\section{Evaluation}

A third component of the integrative seminars is evaluation of the seminar methods, including the use of the ICAM. To explore whether students are developing increased facility with theory-practice integration, students are required to complete case analyses at the first (pretest), fourth (midtest), and final (posttest) seminar classes. The case studies have a similar structure; all involve families that include one latency-aged child with the presenting problem, at least one older adolescent child, and a grandparent living with the family. Cases vary by presenting problems, socioeconomic status, race, culture, sexual orientation, and agency context. Students respond to a series of eight questions or directives. They are (1) define the problem; (2) identify the relevant data; (3) formulatehypotheses about what is going on in the family; (4) choose a theory to analyze the family situation; (5) identify an appropriate practice model to direct the interventions; (6) identify goals; (7) describe intervention strategies; and (8) describe how to evaluate intervention effectiveness with the client.

Shortly after completion of thestudents' case analyses, the data are reviewed and qualitatively analyzed by the authors. Students' analyses are evaluated for coherence, sophistication, and appropriateness. The results serve two purposes.

First, the data provide guidance to the field seminar faculty in planning what to emphasize in field seminar classes. The pretest provides a baseline of student competence, whereas the midtest provides feedback on student progress throughout the trimester. This gauge of student competence or learning is used to modify seminar sessions. For example, after the first trimester of the 2002 seminar, the authors noted that students had made progress in their ability to think theoretically about their clients and to choose a practice model consistent with their theory. They had difficulty translating that, however, into the development of coherent, well-defined goals. Consequently, the first class session of the next trimester included an additional focus on goal setting.

The second purpose is to evaluate the effectiveness of the ICAM and the seminar structure in building linkages for students between theory and practice. Unlike previous research efforts that have relied largely on student satisfaction as measures of seminar outcome (Mary \& Herse, 1992; 
Waltersetal.,1998; Wilsonetal.,2001), this evaluation consists of a series of written case analyses in which students demonstrate their developing facility with theory-practice integration.

\section{Discussion}

This model and field seminar format evolved from a realization by the authors that students in their field seminars lacked the ability to identify, understand, and apply theory to their work with clients. As a group, students lacked a systematic approach to their thinking about client issues, which is considered to be critical to guiding their clinical decision making. Students had difficulty identifying the variety of theories they were applying in a case or presenting an approach with a client that illustrated coherence in thinking from the first phase of practice to the last. Further, despite the initiation of a systematic oral presentation approach to cases in the field seminar classes, significant gains were not realized. Thus, this model and field seminar format are predicated on the belief that students must be provided with a conceptual framework, structured assignments, and teaching methods that help organize their thinking and enhance the integration of theory and practice.

The implementation of this model, however, requires a certain degree of acumen from both the field seminar instructor and the students. Without notice, the field seminar instructor must be able to identify, articulate, and apply theories and models to the cases that students present. This can be a daunting and confusing task. Not only must the instructor be conversant with numerous basic and applied theories, but the contradictory nature of the social work literature related to theories and models can be confounding-toinstructors as well as students.
Because of the pedagogical demands and the need for regular consultation, faculty who are teaching full-time may be in the best position to teach these field seminars.

Theauthors believe this model is bestsuited to a student's final graduate field practicum. Typically students in a first placement are becoming acclimated to the agency culture and their roles. They are focused on becoming familiar with agency-based practice, developing beginning social work skills, and achieving a comfort level with clients. As a group, they do not have a sufficient knowledge base and are notdevelopmentally ready tobe concerned with all of the components of the ICAM.

The authors are continuing their research to further elucidate students' progress in the area of integration of theory and practice. Guided by individualized learning theory, students in field seminars this year are not only completing case analyses, but have taken a personal learning style inventory. The goal is to assess how students with different learning styles fare using the ICAM. Does the ICAM need to be adapted for different learning styles? Dostudents need to bejoined at their most comfortable learning style and proactively moved through the process? (The term "join" refers to the method whereby the educator starts the instructional process by directing educational activities to the dominant learning style of the student. For example, if the studenthas a predominantly concretesequential learning style, the instructor might construct initial learning activities that allow the student to use this mode of learning.)

Should the evaluations continue to show positive gains for students in conceptualizing the issues and intervening with clients, this model must be taught more systematically 
to field instructors. Given the research (Bogo \& Power, 1992; Rogers \& McDonald, 1995) on field instructors' perceptions of the importance of teaching theory, there must be an open dialogue with those who are unconvinced about the essential role integration plays in preparing students to become quality MSW practitioners. Further, as indicated by Raskin's field experts (1994), field instructors must be taught the model and methods to achieve that goal.

However, a larger question remains. Does teaching students a systematic approach to practice that includes a theoretical knowledge base that can be identified and applied to one's clients enhance one's clinical skills? Are students armed with this knowledge base more effective in their work with clients? This has been the assumption insocialworkliterature.Futureresearchisneeded in this area to substantiate this assumption.

In conclusion, just as students' practice should be grounded in theory, educators' pedagogy in the field should be grounded in theory. We believe this model and field seminar format to be another step in the quest for effectively responding to the dilemma of integrating theory and practice.

\section{References}

Barsky, A., Rogers, G., Krysik, J., \& Langevin, P. (1997). Evaluating the integration of social work theory and practice: Multi-modal teaching techniques in the classroom. Canadian Social Work Review, 14, 185-200.

Beder, J. (2000). The integration of theory into practice: Suggestions for supervisors. Professional Development: The International Journal of Continuing Social Work, 3, 40-48.

Berlin, S. B., \& Marsh, J.C. (1993). Informing practice decisions. New York: Macmillan.
Birnbaum, M. L. (1984). Theintegration of didactic and experiential learning in the teaching of group work. Journal of Social Work Education, 20, 56-57.

Bogo, M., \& Power, R. (1992). New field instructors' perceptions of institutional supports for their roles. Journal of Social Work Education, 28, 178-189.

Bogo,M., \&Vayda,E. (1989). Developing a process model for field instruction. Canadian Social Work Review, 6, 224-232.

Bogo, M., \& Vayda, E. (1998). The practice of field instruction in social work: Theory and process (2nd ed.). New York: Columbia University Press.

Fortune, A. E., McCarthy, M., \& Abramson, J. S. (2001). Student learning processes in field education: Relationship of learning activities to quality of field instruction, satisfaction, and performance among MSW students. Journal of Social Work Education, 37, 111-124.

Gelfand, B. (1990). The reflective log: An essential teaching instrument in assisting students to integrate theory with practice in a communicationlaboratory. Canadian Social Work Review, 2, 273-282.

Gordon, W.,\&Gordon, M. (1982). Therole of frames of reference in field instruction. In B. Sheafor \& L. Jenkins (Eds.), Quality field instruction in social work: Programdevelopmentand maintenance (pp. 1-36). New York: Longman.

Gregorc, A. (1982). An adults' guide to style: Development, technical and administrative manual. Maynard, MA: Gabriel Systems.

Jarman-Rohde, L., McFall, J., Kolar, P., \& Strom, G. (1997). The changing context of social work practice: Implications and recommendations for social work educators. Journal of Social Work Education, 33, 29-42. 
Kolb, D. A. (1984). Experiential learning: Experience as the source of learning and development. Englewood Cliffs, NJ: Prentice-Hall.

Lowy, L., Bloksberg, L. M., \& Walberg, H. J. (1971). Integrative learning and teaching in schools of social work. New York: Associated Press.

Mary, N. L., \& Herse, M. H. (1992). What do field seminars accomplish? Students and instructor perspectives. Journal of Teaching in Social Work, 6, 59-73.

Mok, B. J. (1993). Integrative seminar: A cognitive approach to linking theory and practice in social work. International Social Work, 36, 333-340.

Osmo, R., \& Landau, R. (1998, July). The need for explicit argumentation in ethical decision making in social work. Paper presented at the meeting of the InternationalCouncil forSocial Welfare, Jerusalem, Israel.

Raschick, M., Maypole, D., \& Day, P. (1998). Improving field education through Kolb learning theory. Journal of Social Work Education, $34,31-42$.

Raskin, M. S. (1994). The Delphi study in field instruction revisited: Expert consensus on issues and research priorities. Journal of Social Work Education, 30, 75-89.

Reisch, M., \& Jarman-Rohde, L. (2000). The future of social work in the United States: Implications for field education. Journal of Social Work Education, 36, 201-214.

Rogers, G., \& McDonald, P. L. (1995). Expedience overeducation: Teaching methods used by field instructors. The Clinical Supervisor, 13, 41-65.
Rogers, G., \& Thomlison, B. (1998, March). Promoting critical reflection in the practicum. Paper presented at the annual program meeting of the Council on Social Work Education, Orlando, FL.

Skolnik, L., Wayne, J., \& Raskin, M. S. (1999). A worldwide view of field education structures and curricula. International Social Work, 42, 471-483.

Smith, D., \& Kolb, D. A. (1986). User's guide for the learning style inventory: A manual for teachers and trainers. Boston: McBer.

Tolson, E. R., \& Kopp, J. (1988). The practicum: Clients, problems, interventions and influences on student practice. Journal of Social Work Education, 24, 123-134.

Vayda, E., \& Bogo, M. (1991). A teaching model to unite classroom and field. Journal of Social Work Education, 27, 271-278.

Walden, T., \& Brown, L. N. (1985). The integration seminar: a vehicle for joining theory and practice. Journal of Social Work Education, 21, 13-19.

Walters, G., Strom-Gottfried, K., \& Sullivan, M. (1998). Assembling pieces in the diversity puzzle: A field model. Journal of Social Work Education, 34, 353-363.

Wilson, R. J., Birkenmaier, J., Banks, R., \& BergWeger, M. (2001, March). MSW integrative seminars: A social work odyssey through the curriculum. Paper presented at the annual program meeting of the Council on Social Work Education, Dallas, TX.

Accepted 01/03.

Laura Boisen is associate professor, and Maryann Syers is assistant professor, Department of Social Work, Augsburg College.

Address correspondence to Laura Boisen, Department of Social Work, Campus Box \#51, 2211 Riverside Avenue, Minneapolis, MN 55454; email: boisen@augsburg.edu. 
Copyright of Journal of Social Work Education is the property of Council on Social Work Education and its content may not be copied or emailed to multiple sites or posted to a listserv without the copyright holder's express written permission. However, users may print, download, or email articles for individual use. 